\section{Best practices for transfusion for patients with sickle cell disease}

\author{
Ted Wun, ${ }^{1}$ Kathryn Hassell ${ }^{2}$ \\ 'UC Davis School of Medicine, \\ Sacramento; ${ }^{2}$ University of Colorado \\ at Denver, USA
}

\section{Abstract}

The $\beta$-globin gene mutation in sickle cell anemia results in anemia and repeated bouts of vascular occlusion. The cumulative effect of these vasocclusive events is progressive damage to many organs including the kidneys, lungs, and brain. The transfusion of red blood cells (RBC) can ameliorate many of these complications, but can be associated with both acute and chronic complications, including iron overload. The objective of the Best Practices in Transfusion Medicine for Patients with Sickle Cell Disease (SCD) Conference was to review the available published evidence and clinical experience surrounding the use of RBC transfusions for sickle cell disease by a panel of experts. The expert panel developed explicit clinical guidelines for the use of $\mathrm{RBC}$ in SCD patients. The panel also made recommendations for further research. A set of guidelines were produced for dissemination to pertinent stakeholders. If implemented, these clinical pathways have the potential to optimize the use of red blood cell transfusions in SCD.

\section{Introduction}

Sickle cell anemia was the first recognized "molecular disease". A single DNA base mutation, leading to a single amino acid substitution (Glu to Val), results in hemoglobin $\mathrm{S}(\mathrm{HbS})$, the major hemoglobin defect, and a myriad of clinical manifestations. ${ }^{1}$ Acute clinical manifestations include painful crisis, acute chest syndrome, stroke, and priapism. Irreversible major organ damage occurs to the brain, heart, lungs, kidneys, eyes, and femoral heads. Although anemia accounts for some of the morbidity of sickle cell disease, vascular occlusion underlies most of the acute and chronic complications. ${ }^{1}$ The SCD phenotype is predominantly expressed in those with homozygous S (HbSS), or compound heterozygotes of $\mathrm{HbS}$ and $\mathrm{HbC}(\mathrm{HbSC})$ or $\mathrm{HbS}$ and $\beta$-thalassemia $\left(\mathrm{HbS} / \mathrm{B}^{0}\right.$-thal or $\mathrm{HbS} / \beta^{+}$thal).

There is no doubt that both acute and chronic RBC transfusions, both in the acute and chronic setting, can ameliorate many of the complications of sickle cell disease. ${ }^{2}$ Some transfusion practices, such as perioperative transfusion, ${ }^{3}$ transfusion during pregnancy, ${ }^{4}$ and chronic transfusion to prevent stroke in children found to be high-risk from transcranial doppler (TCD) screening and/or because of previous stroke, ${ }^{5-7}$ are based on prospective randomized studies. Other practices, such as transfusion for prolonged painful episodes, exchange transfusion for acute chest syndrome, and RBC transfusion for those with pulmonary hypertension, are based on less firm evidence. ${ }^{2}$ Barriers to chronic transfusion therapy include patient and family reluctance, inconvenience, intravenous access issues, alloimmunization, red cell availability, infectious disease complications, immune modulation, and iron overload. ${ }^{8}$ Based on surveys from the Sickle Cell Adult Provider Network (SCAPN), whereas transfusion practice for patients with pregnancies is fairly standard, it varies considerably in adults with ischemic stroke (K. Hassell, unpublished communication)

It was recognized that many practices and recommendations regarding transfusion of RBC for patients with SCD were not evidenced based. Nonetheless, it was felt important to highlight those that did have a basis in prospective, randomized trials, and to catalog practices that were in common use but not evidenced based. At a minimum, such a catalog could serve as a basis for critically examining current practices and setting research priorities for future studies. The overall purpose of the conference was to provide succinct best practices guidelines for transfusion that had the potential to improve care. ${ }^{9}$

\section{Materials and Methods}

This conference was conceived to be part of a series of five best practices guidelines focusing on the care of adult patients with SCD. This conference was not a "consensus" conference, nor was it an exhaustive, meta-analyses or Cochrane-type review of the literature. Rather, it was a focused literature review with key citations as determined by experts in the field. For a more comprehensive overview, the reader is directed to several excellent reviews on this topic. ${ }^{2,10-12}$ Several months prior to the meeting, the conference coordinator (TW) asked each invited expert (Table 1) to forward succinct recommendations for each assigned topic and provide key citations. These served as the basis for the agenda.

The conference took place September, 2007 immediately preceding the annual Sickle Cell Clinical Research Meetings and was open to the public. Each expert was asked to present her or his recommendations and assign a strength based on a simplified scoring system of Strong, Moderate, or Uncertain (Table 2)
Correspondence: Ted Wun, Division of Hematology and Oncology, UC Davis Cancer Center, 4501 X Street, Sacramento, CA 95817, USA E-mail: twun@ucdavis.edu

Key words: sickle cell, transfusion, guidelines.

Funding: supported by an R13 (HL090075) grant from the NHLBI and the Office of Rare Diseases (T.W.) and by the UC Davis Clinical and Translational Science Center and National Center for Research Resources (UL1 RR024146)

Received for publication: 7 September 2009. Accepted for publication: 27 November 2009.

This work is licensed under a Creative Commons Attribution 3.0 License (by-nc 3.0)

(C) Copyright T. Wun and K. Hassel, 2009

Licensee PAGEPress, Italy

Hematology Reviews 2009; 1:e22

doi:10.4081/hr.2009.e22

that paralleled ones used in other guideline recommendations..$^{13}$ At the end of each presentation, comment was invited from the audience and other panel members. The final recommendations were developed by consensus at the end of the conference with audience input.

Panel members adhered to several principles while developing their recommendations. First, in keeping with the theme, best practices, as opposed to standard or practical ones, were to be recommended. The bar was to be set high to promote what was felt to be optimal medical care. Second, recommendations were to be evidence-based if possible, but could also be based on expert opinion. This was in recognition that very little available data was truly evidenced-based. In the absence of data specific to adults, discussants were asked to extrapolate from data in children. Finally, panel members were asked to be as prescriptive as possible, without being dogmatic.

\section{Results}

A set of guidelines were produced for dissemination to pertinent stakeholders.

\section{Recommendation \#1: indications for acute red blood cell transfusions}

Transfusion is indicated for the therapy of the acute clinical situations detailed in Table 3 . This recommendation was strong for acute chest syndrome (ACS) with hypoxemia or worsening respiratory distress, ${ }^{14,16}$ ischemic stroke without or without post-infarct bleeding, ${ }^{8,17}$ splenic and hepatic sequestration with worsening anemia, aplastic crisis with worsening anemia, symptomatic acute blood loss, 
and multiorgan failure. ${ }^{18}$ It was acknowledged that there is neither a universal definition of acute chest syndrome, nor a system for grading the severity of ACS. ${ }^{14-16}$ Nonetheless, all panel members agreed that hypoxemia requiring supplemental oxygen and/or worsening tachypnea were indications. It was also recognized that the term "significant decrease from baseline" in regards to splenic and hepatic sequestration is subjective. This determination is best made by clinicians under specific clinical circumstances. For isolated intracerebral hemorrhage, transfusions are of uncertain benefit and, anecdotally, have exacerbated central nervous system (CNS) bleeding. Nonetheless, in cases where there was an infarctive component to the bleed, some panel members felt that transfusion might be useful. Panel members were in more agreement about transfusion for transient ischemic attacks (TIA), but there are some data suggesting that transfusions are not effective at prevention: ${ }^{19}$ however, in the absence of clinical trials, this recommendation was graded as only moderate. Silent cerebral infarcts (SCI) were not addressed at this conference, but there are some data to suggest that transfusion may lower the incidence of SCI as defined by MRI. ${ }^{20}$ However, as these data were generated in children who would be considered candidates for transfusion therapy regardless (because of high risk TCD findings), a separate recommendation may not be necessary. The indications for red blood cell transfusion for severe infections and persistent priapism are based on less convincing anecdotes and are thus uncertain..$^{21}$ The association of sickle cell disease, priapism, exchange transfusion, and neurological events (ASPEN syndrome) was also of concern regarding transfusion therapy for priapism. ${ }^{21,22}$ Because the ASPEN syndrome is based largely on case reports, there was insufficient evidence to consider priapism a contraindication to transfusion. A recent report suggested that exchange transfusion was safe and efficacious if the resulting hemoglobin level was $<11 \mathrm{~g} / \mathrm{dL},{ }^{22}$ suggests that ASPEN syndrome results from increased whole blood viscosity.

\section{Recommendation \#2: red cell transfusion is not indicated for the therapy of uncomplicated acute painful episodes regardless of duration}

The panel discussed that RBC transfusion during otherwise typical painful episodes was common in both community and academic settings but there was little to no evidence to support this practice. ${ }^{23}$ The term uncomplicated in this context means without the indications for acute transfusion stated in recommendation \#1. The panel felt that this practice should be discouraged, therefore warranted a separate recommendation to emphasize the point.

Table 1. Speakers and topics.

Marilyn J. Telen, M.D., Wellcome Professor of Medicine and Chief of Hematology, Duke University Medical Center

Indications for acute and chronic red cell transfusions

Naomi L.C. Luban, M.D., Professor of Pediatrics and Pathology, Chief of Laboratory Medicine and

Pathology, Children's National Medical Center

Selection of the appropriate red cell product

Paul V. Holland, M.D., Clinical Professor of Medicine and Pathology, UC Davis School of Medicine

Infectious and immunologic complications of transfusion in patients with SCD

Paul Swerdlow, M.D., Professor of Medicine, Wayne State University School of Medicine

Exchange versus simple transfusion, $\mathrm{Hb}$ and $\mathrm{HbS}$ target

Elliot P. Vichinsky, M.D., Director, Hematology and Oncology, Children's Hospital Oakland Research Institute

Perioperative transfusions

Gary Brittenham, M.D., Professor of Medicine and Pediatrics, Columbia University College of Physicians and Surgeons

Assessment and Management of iron overload in patients with SCD

Table 2. Definition of grading.

\section{Strong arm was considered unethical by the panel \\ Moderate \\ Prospective, randomized data from children \\ Definitive study is thought not feasible by the panel \\ Uncertain \\ Retrospective studies or case reports in adults or children \\ Recommendation \#3: acute red cell transfusion is not indicated for a decrease in hemoglobin from baseline not associated with symptoms of anemia}

At least one, prospective randomized study in adults or a randomized study where a non-transfusion

Prospective, non-randomized or observational studies in adults or children

In a certain sense, this recommendation is in concert with \#2. Patients with SCD have variable severity of chronic anemia. Physiological compensation includes high cardiac output and increased plasma volume. The practice of routine transfusion for an arbitrary level of hemoglobin should be discouraged in SCD patients and all patients. The panel emphasized that patients with chronic anemia may be more sensitive to volume challenge and prone to develop symptomatic volume overload. Whether a patient tolerates a specific level of hemoglobin depends on the clinical circumstances (e.g., infection, rapidity of decline, co-morbid conditions) and the determination of whether the anemia is "symptomatic" is somewhat subjective. This recommendation is dependent on sound clinical judgment.

\section{Recommendation \#4: prophylactic red cell transfusions}

Red cell transfusions can be used in the prevention of sickle cell complications. The panel felt that these should be strongly recommended for high risk surgical procedures, ${ }^{3,24,25}$ secondary prevention of stroke, and primary prevention of stroke in those children identi- fied as high risk by TCD examination..$^{5,7}$ In patients requiring general anesthesia with evidence of cardiac, pulmonary, renal, or hepatic dysfunction, many panelists and attendees also felt red cell transfusions were indicated. The panel discussed general anesthesia is likely not the issue, but rather procedure times of 45-60 minutes or longer place patients at higher risk for complications, predominantly pulmonary. There was disagreement as to what constituted a high risk surgical procedure. There was agreement that open thoracic and vascular procedures were high risk, but hip and knee replacement might be considered moderate risk (similar to cholecystectomy). Abdominal procedures may also be associated with increased risk, particularly in patients with HbSC disease. ${ }^{26}$ Anecdotal experience suggests that prophylactic transfusions can reduce the frequency of painful episodes in patients refractory to hydroxyurea, but only as part of a comprehensive pain program.

\section{Recommendation \#5: chronic transfusion may be useful in stabilizing or reversing certain end-organ dysfunction}

These include pulmonary hypertension, congestive heart failure, and renal dysfunction. However, this recommendation is almost entirely based on personal experience and/or anecdotal reports. Many participants observed 
that aggressive local therapy was the most effective treatment for non-healing leg ulcers. As the sickle cell population ages and develops more chronic end-organ dysfunction, this will be an important area for research.

\section{Recommendation \#6: type of red cell product}

The red blood cell products used for transfusion in patients with SCD should all be leukocyte-reduced, sickle hemoglobin negative, matched for at least the red cell antigens $\mathrm{Cc}$, $\mathrm{Ee}$, and $\mathrm{K}$ and any antigens for which the patients has developed alloantibodies (past or present). Alloimmunization to red cell antigens is a common occurrence in transfused SCD patients. ${ }^{27,28}$ Limited phenotype-matching has been shown to decrease significantly the rate of alloimmunization amongst non-alloimmunized sickle cell patients. ${ }^{29}$ Recent studies showed that limited phenotype-matching is practiced by a minority of transfusion medicine services surveyed in North America. ${ }^{30}$ Discussion centered on the fact that not all cellular blood products in the US are pre-storage leukocyte reduced. While this is the standard in the European Union and the United Kingdom, only about $70 \%$ of blood banks in the United States routinely stock pre-storage leukocyte reduced products. Not all transfusion medicine services verify that blood being transfused to a SCD patient is sickle hemoglobin negative. In areas where there is a large African American blood donor population, this issue becomes more relevant.

\section{Recommendation \#7: target hemogoblin level}

When transfusing red blood cells for acute indications, the target hemoglobin and hematocrit level should not exceed $10 \mathrm{~g} / \mathrm{dL}$ and $30 \%$, respectively. The panel and audience believed that there were sufficient rheological data and rationale to avoid higher levels to prevent increases in whole blood viscosity. ${ }^{31-33}$ In addition, there is some clinical evidence suggesting that acute clinical deterioration occurs when whole blood viscosity is suddenly increased (ASPEN Syndrome noted above). The panel acknowledged that much of the data were generated in vitro; nonetheless, this recommendation was strong.

\section{Recommendation \#8: target $\mathrm{HbA}$ level}

For acute exchange transfusions, a level of $\mathrm{HbA} \%>70 \%$ should be targeted. It was acknowledged that this has never been rigorously studied. Establishing a target in terms of the percentage of $\mathrm{HbA}$ rather than $\mathrm{HbS}$ was more sensible for compound heterozygous patients. For example, it is simpler to target raising the $\mathrm{HbA}$ to $70 \%$ in a patient with $\mathrm{HbSC}$ than to target a
Table 3. Recommendations.

$\# 1$

Acute complications requiring acute red cell transfusion

Acute Chest Syndrome with hypoxemia, or increasing respiratory distress (Strong)

Without hypoxemia or increasing respiratory distress (Moderate)

Acute stroke (ischemic with or without bleed) (Strong)

Isolated intracranial hemorrhage (Uncertain with caveat)

TIA (Moderate)

Retinal Artery Occlusion (Moderate)

Acute splenic sequestration with a significant drop from baseline $\mathrm{Hb}$ (Strong)

Acute hepatic sequestration (Strong)

Aplastic crisis (Strong)

Significant, symptomatic acute blood loss (Strong)

Persistent priapism (Uncertain)

Multiorgan failure syndrome (Strong)

Acute life-threatening infection (Uncertain)

\#2

Acute red cell transfusion is not indicated for the therapy of uncomplicated painful episodes regardless of duration (Strong)

$\# 3$

Acute red cell transfusion is not indicated for a decrease in hemoglobin from baseline not associated with symptoms of anemia (Strong)

$\# 4$

Prophylactic red cell transfusions are indicated for

High risk surgical procedures (Strong)

Surgical procedure requiring anesthesia in a patient with evidence of significant end-organ dam-

age (Moderate)

Cardiac, pulmonary, renal, hepatic insufficiency (Uncertain)

Secondary prevention of stroke (Strong)

For patients who had strokes as children and are now adults (Moderate)

Primary prevention of stroke for patients who were identified as children as being high risk (Strong)

Refractory (to hydroxyurea), frequent painful episodes same evidence as a component

of a comprehensive pain protocol (Moderate)

Exacerbation of SCD during pregnancy (Moderate)

Consider if acute $\mathrm{Hb}<6.0 \mathrm{~g} / \mathrm{dL}$ (Moderate)

\#5

Chronic transfusion may be useful in stabilizing or reversing

Progressive congestive heart failure (Moderate)

Progressive chronic renal insufficiency (Uncertain)

Progressive pulmonary hypertension (Uncertain)

Elevated tricuspid regurgitant jet (Uncertain)

Non-healing leg ulcer (Uncertain)

$\# 6$

The red blood cells given to patients with sickle cell disease should be

Leukocyte-reduced (pre-storage strongly preferred) (Strong)

Antigen-matched for $\mathrm{Cc}$, Ee, $\mathrm{K}$ and any antigens for which there is a clinically significant alloanti-

body currently present or in the past (Strong)

Hemoglobin S negative (Strong)

\#7

For acute sickle cell complications, the dose of red cells should be calculated to result in a Hb

$\leq 10 \mathrm{~g} / \mathrm{dL}$ or $\leq$ Hct $30 \%$ (Strong)

\#8

The goal of exchange transfusion for acute indications is to achieve a $\mathrm{HbA}>70 \%$ on post-transfusion hemoglobin fractionation (Strong)

The preferred method is erythrocytapheresis with residual $\mathrm{HbS}<30 \%$ (Strong)

$\# 9$

Exchange transfusion is preferred over simple transfusion in adults for

Acute stroke (Strong)

Severe acute chest syndrome (Strong)

Multi-organ failure (Strong)

Preoperative transfusion with baseline $\mathrm{Hb}>10 \mathrm{~g} / \mathrm{dL}$ (Moderate)

Transfusion of volume sensitive patients (Moderate)

Hyperosmolar contrast agents (Uncertain)

Refractory priapism (Uncertain)

$\# 10$

Every patient with sickle cell disease should be vaccinated for hepatitis A/B (Strong)

continued on next page 
Table 3. Continued.

\#11

Patients with sickle cell disease who are intermittently or repeatedly transfused should be periodically evaluated for iron overload. Iron-chelating therapy with deferasirox or deferoxamine should be used to maintain the body iron burden in an optimal range that reduces the risk of iron toxicity while avoiding adverse effects of excessive chelator administration (Strong)

$\# 12$

Each patient with sickle cell disease should have a comprehensive transfusion record, including phe type, type and number of transfusions, and adverse events

$\# 13$

There should be a system for sharing information on phenotype and alloantibody information amongst regional blood providers

HbS of $15 \%$ and $\mathrm{HbC}$ of $15 \% .^{11}$ The preferred method for exchange is automated erythrocytapheresis. In the absence of an apheresis service or because of patient preference, manual exchange is a suitable alternative. ${ }^{17}$

\section{Recommendation \#9: simple vs exchange transfusion}

There are few data comparing simple to exchange transfusion. Exchange was preferred strongly over simple transfusion for the treatment of severe acute chest syndrome, stroke, and multi-organ failure. A multi-center, randomized study showed exchange transfusion to be non-superior to simple transfusion in the perioperative setting. ${ }^{24}$ However, the panel endorsed the use of exchange as preferable in advance of high risk operations. There was no clarity as to which modality was preferable in the setting of acute priapism and use of hyperosmolar contrast agents, with the latter just to be avoided with the availability of iso-osomotic contrast agents.

\section{Recommendation \#10: vaccination}

Every sickle cell patient should be vaccinated for hepatitis A and B as early as possible to prevent post-transfusion infection. This was non-controversial and strong.

\section{Recommendation \#11: iron assess- ment}

There was consensus that chronically transfused sickle cell disease patients should be regularly assessed for iron overload and offered chelation therapy to decrease the risk of iron related toxicity. There was considerable discussion regarding the number of lifetime transfusions that should trigger an assessment of iron stores, and the optimal methods and extent of this assessment. ${ }^{34}$ The panel noted that some published recommendations are an extrapolation from the experience with $\beta$-thalassemia patients whose iron burden is significantly higher based on pathophysiology of their disease. ${ }^{35-37}$ Despite limited evidence, the consensus of the panel is that the hepatic storage iron concentration should be maintained below a threshold of $15 \mathrm{mg} \mathrm{Fe} / \mathrm{g}$ liver, dry weight, to avoid progression to liver fibro- sis and a target range of 3 to $7 \mathrm{mg} \mathrm{Fe} / \mathrm{g}$ liver, dry weight, is recommended as prudent. Liver biopsy with its inherent risks is still the standard, but MRI T2* can also be used and its availability is only a function of proper calibration. Centers taking care of chronic transfusion patients should develop the ability to offer this mode of iron assessment.

\section{Recommendation \#12}

Every patient with sickle cell disease should have a portable comprehensive transfusion record, including phenotype, type and number of transfusions, alloantibody status and adverse events. Strongly advocated by the patients present, this again would ensure timely provision of appropriate and safer red cell transfusions.

\section{Recommendation \#13: information sharing}

There should be a system for sharing patient information on RBC phenotype, and alloantibody and autoantibody status amongst regional blood providers. While allowing for privacy concerns, this was felt to be necessary to avoid further alloimmunization, hemolytic transfusion reactions due to anamnestic alloantibody responses (which may simulate acute aplasia and crisis $^{38}$ ), and help ensure availability of appropriately selected RBC products. This recommendation was stressed by patients and family members in attendance.

\section{Conclusions}

If implemented, these clinical pathways have the potential to optimize the use of red blood cell transfusions in SCD.

\section{References}

1. Francis RB, Johnson CS. Vascular occlusion in sickle cell disease: current concepts and unanswered questions. Blood 1991;77:1405-14.
2. Wanko S0, Telen MJ. Transfusion management in sickle cell disease. Hematol Oncol Clin North Am 2005;19:803-8.

3. Vichinsky EP, Neumayr LD, Haberkern C et al. The perioperative complication rate of orthopedic surgery in sickle cell disease: report of the National Sickle Cell Surgery Study Group. Am J Hematol 1999;62:12938.

4. Koshy M, Burd L, Wallace D et al. Prophylactic red-cell transfusions in pregnant patients with sickle cell disease. A randomized cooperative study. N Engl J Med 1988;319:1447-52.

5. Adams RJ, Brambilla DJ, Granger S et al. Stroke and conversion to high risk in children screened with transcranial Doppler ultrasound during the STOP study. Blood 2004;103:3689-94.

6. Adams RJ, McKie VC, Brambilla D et al. Stroke prevention trial in sickle cell anemia. Control Clin Trials 1998;19:110-29.

7. Adams RJ, McKie VC, Hsu L et al. Prevention of a first stroke by transfusions in children with sickle cell anemia and abnormal results on transcranial Doppler ultrasonography. N Engl J Med 1998;339:511.

8. Telen MJ. Principles and problems of transfusion in sickle cell disease. Semin Hematol 2001;38:315-23.

9. Olson V, Coyne P, Smith V, Hudson C. Critical pathway improves outcomes for patients with sickle-cell disease. Oncol Nurs Forum 1997;24:1682.

10. Josephson CD, Su LL, Hillyer KL, Hillyer CD. Transfusion in the patient with sickle cell disease: a critical review of the literature and transfusion guidelines. Transfus Med Rev 2007;21:118-33.

11. Swerdlow PS. Red cell exchange in sickle cell disease. Hematology Am Soc Hematol Educ Program 2006:48-53.

12. Minniti CP, Kratovil T, Luban NL. Children's National Medical Center's transfusion protocol for sickle hemoglobinopathies. Immunohematology 2006;22: 117-20.

13. Proceedings of the Seventh ACCP Conference on Antithrombotic and Thrombolytic Therapy: evidence-based guidelines. Chest 2004;126:172S-696S.

14. Golden C, Styles L, Vichinsky E. Acute chest syndrome and sickle cell disease. Curr Opin Hematol. 1998;5:89-92.

15. Morris C, Vichinsky E, Styles L. Clinician assessment for acute chest syndrome in febrile patients with sickle cell disease: is it accurate enough? Ann Emerg Med 1999; 34:64-9.

16. Vichinsky EP, Neumayr LD, Earles AN et al. Causes and outcomes of the acute chest syndrome in sickle cell disease. National Acute Chest Syndrome Study Group. N Engl J Med 2000;342:1855-65. 
17. Wayne AS, Kevy SV, Nathan DG. Transfusion management of sickle-cell disease. Blood 1993;81:1109-23.

18. Hassell KL, Eckman JR, Lane PA. Acute multiorgan failure syndrome: a potentially catastrophic complication of severe sickle cell pain episodes. Am J Med 1994;96:15562.

19. Pegelow CH, Adams RJ, McKie V et al. Risk of recurrent stroke in patients with sickle cell disease treated with erythrocyte transfusions. J Pediatr 1995;126:896-9.

20. Pegelow $\mathrm{CH}$, Wang W, Granger $\mathrm{S}$ et al. Silent infarcts in children with sickle cell anemia and abnormal cerebral artery velocity. Arch Neurol 2001;58:2017-21.

21. Merritt AL, Haiman C, Henderson SO. Myth: blood transfusion is effective for sickle cell anemia-associated priapism. CJEM 2006;8:119-22.

22. Ballas SK, Lyon D, Hall N, Kent T. Safety of blood exchange transfusion for priapism complicating sickle cell disease. J Clin Apheresis 2006;21:16.

23. Ballas SK. Management of sickle pain. Curr Opin Hematol 1997;4:104-11.

24. Vichinsky EP, Haberkern CM, Neumayr L et al. A comparison of conservative and aggressive transfusion regimens in the perioperative management of sickle cell disease. The Preoperative Transfusion in Sickle Cell Disease Study Group. N Engl J
Med 1995;333:206-13.

25. Vichinsky EP. Current issues with blood transfusions in sickle cell disease. Semin Hematol 2001;38:14-22.

26. Neumayr L, Koshy M, Haberkern C et al. Surgery in patients with hemoglobin SC disease. Preoperative transfusion in Sickle Cell Disease Study Group. Am J Hematol 1998;57:101-8.

27. Vichinsky EP, Earles A, Johnson RA et al. Alloimmunization in sickle cell anemia and transfusion of racially unmatched blood. N Engl J Med 1990;322:1617-21.

28. Orlina AR, Unger PJ, Koshy M. Post-transfusion alloimmunization in patients with sickle cell disease. Am J Hematol 1978; 5:101-6.

29. Vichinsky EP, Luban NL, Wright E et al. Prospective RBC phenotype matching in a stroke-prevention trial in sickle cell anemia: a multicenter transfusion trial. Transfusion 2001;41:1086-92.

30. Osby M, Shulman IA. Phenotype matching of donor red blood cell units for nonalloimmunized sickle cell disease patients: a survey of 1182 North American laboratories. Arch Pathol Lab Med 2005;129:190-3.

31. Dintenfass L. Rheology of packed red blood cells containing hemoglobins a-a, S-a, and S-S. J Lab Clin Med 1964;64:594-600.

32. Huber H, Lewis SM, Szur L. The influence of anaemia, polycythaemia and spleno- megaly on the relationship between venous haematocrit and red-cell volume. Br J Haematol 1964;10:567-75.

33. Schmalzer EA, Lee J0, Brown AK et al. Viscosity of mixtures of sickle and normal red cells at varying hematocrit levels. Implications for transfusion. Transfusion 1987;27:228-33.

34. Harmatz P, Butensky E, Quirolo K et al. Severity of iron overload in patients with sickle cell disease receiving chronic red blood cell transfusion therapy. Blood 2000; 96:76-9.

35. Brittenham GM, Badman DG. Noninvasive measurement of iron: report of an NIDDK workshop. Blood 2003;101:15-9.

36. Brittenham GM, Cohen AR, McLaren CE et al. Hepatic iron stores and plasma ferritin concentration in patients with sickle cell anemia and thalassemia major. Am J Hematol 1993;42:81-5.

37. Brittenham GM, Sheth S, Allen CJ, Farrell DE. Noninvasive methods for quantitative assessment of transfusional iron overload in sickle cell disease. Semin Hematol 2001;38:37-56.

38. Diamond WJ, Brown FL, Bitterman P et al. Delayed hemolytic transfusion reaction presenting as sickle-cell crisis. Ann Intern Med 1980;93:231-3. 